\title{
A foregoing thenar muscular branch of the median nerve
}

\author{
Samet Vasfi Kuvat, Levent Özçakar ${ }^{1}$, Memet Yazar \\ Department of Plastic and Reconstructive Surgery, Diyarbakır and Istanbul, ${ }^{1}$ Department of Physical Medicine and \\ Rehabilitation, Ankara, Turkey.
}

Address for correspondence: Dr. Samet Vasfi Kuvat, Seyitömer Mah. Emrullah Efendi Sok. No: 60/6 Fındıkzade 34098 Fatih, İstanbul, Turkey. E-mail: sametkuvat@yahoo.com

\section{ABSTRACT}

We present a 62-year-old female patient who had an anatomic variation in the median nerve of the left hand. During surgery for releasing the left carpal tunnel, an abnormally high level of origin of the thenar muscular branch of the median nerve was detected, at $2.5 \mathrm{~cm}$ above the proximal border of transverse carpal ligament. It traveled between the medial side of the flexor carpi radialis tendon and median nerve and entered the carpal tunnel. After exiting the carpal tunnel distally, the nerve, was noted to course towards the thenar area. Such variations in the median nerve should be kept in mind while performing carpal tunnel release.

\section{KEY WORDS}

Median nerve; motor branch; anatomical variations

\section{INTRODUCTION}

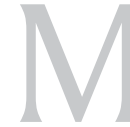

otor branch or recurrent branch of the median nerve, also called as the thenar branch, innervates the intrinsic muscles of the thumb (abductor pollicis brevis, opponens pollicis, and the superficial head of the flexor pollicis brevis). It has an important role in the movements of the thumb and thus in many activities of the hand. Accordingly, hand surgeons pay attention not to injure the motor branch while performing carpal tunnel surgery. ${ }^{[1,3]}$ Herein, a rare anatomic variation regarding the motor branching of the median nerve is being reported.

\section{CASE REPORT}

During surgery for releasing the left carpal tunnel in a 62-year-old lady, the thenar muscular branch of the median nerve was observed to originate $2.5 \mathrm{~cm}$ above the proximal border of the transverse carpal ligament [Figure 1]. It traveled along the medial side of the flexor carpi radialis tendon. By entering the carpal tunnel, the motor branch, along with the median nerve, was noted to course towards the thenar area distal to the transverse carpal ligament. It entered the thenar compartment in an intramuscular fashion [Figure 2]. The medial and lateral divisions of the median nerve were normal in appearance under the carpal tunnel and there were no pseudoganglion formation.

\section{DISCUSSION}

The motor branch of the median nerve was, in relation to the transverse carpal ligament, was found to be of extraligamentous, subligamentous, transligamentous types in $46 \%, 31 \%, 23 \%$, respectively in 246 carpal tunnel release operations by Lanz. ${ }^{[3]}$ Siverhus et al. ${ }^{[4]}$ while studying 72 hands of 36 cadavers, reported the classical distal (extraligamantous-subligamantous) branching in $86 \%$, and transligamentous motor branching in the rest. While Linburg and Albright,,$^{[5]}$ Rockwell ${ }^{[6]}$ reported multiple motor branching anomalies, Graham ${ }^{[7]}$ referred 


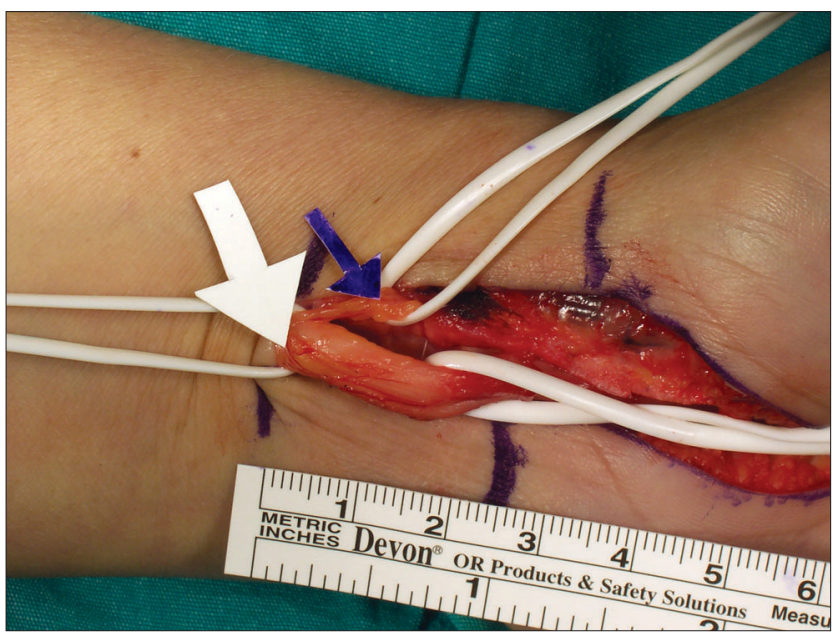

Figure 1: Intraoperative photograph demonstrating motor branching of the median nerve proximal to the transverse carpal ligament

to a case with motor branching in the ulnar region. Lanz $^{[3]}$ and Gruber ${ }^{[8]}$ found upper level median and lateral division branching (in the distal forearm) in four cases. Eiken et al. ${ }^{[9]}$ reported three similar cases and Kessler reported one case with the same anomaly. ${ }^{[10]}$ However, all those reports were of medial and lateral divisions of the median nerve at the upper level. ${ }^{[3]}$ The upper level branching of only the motor branch is reported in the series of Olave et al. ${ }^{[1]}$ in one case. Likewise in our case, only the motor branch branched out from the median nerve distally in the forearm. The sensory branch of the median nerve (medial and lateral divisions) was inside the carpal tunnel.

While releasing carpal tunnels a proper understanding of the anatomic variations of the motor branch is paramount in order not to cause iatrogenic injuries that may compromise hand functions severely.

\section{REFERENCES}

1. Olave E, Prates JC, Del Sol M, Sarmento A, Gabrielli C.

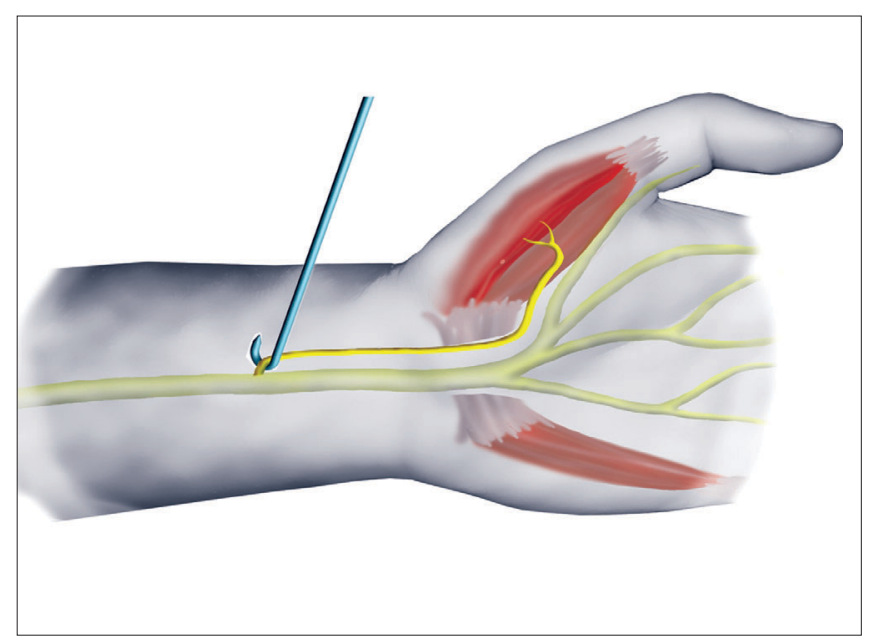

Figure 2: Illustration showing the course of motor branching of the median nerve

Distribution patterns of the muscular branch of the median nerve in the thenar region. J Anat 1995;186:441-6.

2. Chung KC, Walters MR, Greenfield ML, Chernew ME. Endoscopic versus open carpal tunnel release: A cost-effectiveness analysis. Plast Reconstr Surg 1998;102:1089-99.

3. Lanz U. Anatomical variations of the median nerve in the carpal tunnel. J Hand Surg Am 1977;2:44-53.

4. Siverhus SW, Kremchek TE, Smith WR, Basch TM, Drake RL. A cadaveric study of the anatomic variations of the recurrent motor branch of the median nerve. Orthop Rev 1989;18:315-20.

5. Linburg RM, Albright JA. An anomalous branch of the median nerve: A case report. J Bone Joint Surg Am 1970;52:182-3.

6. Rockwell WB, Stone B, Zakhireh M. Three thenar motor branches of the median nerve. Ann Plast Surg 2001;46:661-2.

7. Graham WP 3rd. Variations of the motor branch of the median nerve at the wrist: Case report. Plast Reconstr Surg 1973;51: 90-2.

8. Gruber W. Queen's Elements of Anatomy. Longman's, London: Green and Co; 1987. p. 303.

9. Eiken O, Carstam N, Eddeland A. Anomalous distal branching of the median nerve: Case reports. Scand J Plast Reconstr Surg 1971;5:149-52.

10. Kessler I. Unusual distribution of the median nerve at the wrist: A case report. Clin Orthop Relat Res 1969;67:124-6.

Source of Support: Nil, Conflict of Interest: None declared. 